\title{
Analysis of Glaucoma Subtypes and Corresponding Demographics in a New Zealand Population
}

\author{
Jeremy J. Mathan Dipika V. Patel Charles N.J. McGhee Hussain Y. Patel \\ Department of Ophthalmology, New Zealand National Eye Centre, Faculty of Medical and \\ Health Sciences, University of Auckland, Auckland, New Zealand
}

\begin{abstract}
What Is It about?
This article sought to determine the distribution of diagnoses and demographics of a glaucoma population at a tertiary level eye care facility in New Zealand and to discuss possible explanations for the apparent findings.
\end{abstract}

\section{Key Words}

Glaucoma · Demographics · Maori · Pacific Island Nations · New Zealand

\begin{abstract}
Purpose: The aim of this paper was to determine the diagnosis distribution and demographic characteristics of glaucoma in a New Zealand population. Methods: The clinical records of all patients presenting consecutively to the Auckland District Health Board Glaucoma Service over a 6-month period were reviewed. Demographic parameters including ethnicity, age at presentation, and gender were collected along with all clinical data. Results: The case records of 857 patients were reviewed. Primary open-angle glaucoma (POAG) was the most common diagnosis $(39.0 \%, n=235)$, followed by primary-angle closure (PAC) diagnoses $(24.8 \%, n=$ 149). This group was formed by the combination of narrow angle $18.1 \%(n=109)$, narrowangle glaucoma $0.3 \%(n=2)$, PAC $2.1 \%(n=13)$, and PAC glaucoma $4.2 \%(n=25)$. Normaltension glaucoma (NTG; $17.4 \%, n=105$ ), secondary glaucoma (SG; 11.5\%, $n=69$ ), ocular hypertension $(5.0 \%, n=30)$, and mixed mechanism $(2.3 \%, n=14)$ were also found. There was a significant difference in the ethnic distribution in the study population compared to the catchment population $(p<0.001)$. Caucasian and Indian ethnicities were overrepresented, whereas the Pacific Island Nation ethnicity was underrepresented in all groups except SG. The Maori ethnicity was underrepresented in all groups except PAC. The underrepresentation was most prominent in POAG (only 2 patients of Pacific origin and 1 Maori patient with POAG). Significant differences were identified in gender distribution including a higher preponderance of
\end{abstract}


females in NTG and PAC. Significant differences in age at presentation were also identified between different glaucoma subtypes and ethnicities. Markers of glaucoma severity did not vary with respect to demographic characteristics. Conclusion: In a tertiary glaucoma service in New Zealand, Maori, Pacific peoples, and, to a lesser extent, Asians are underrepresented, while Caucasians and Indians are overrepresented in the glaucoma population.

(C) 2016 The Author(s)

Published by S. Karger AG, Basel

\section{Introduction}

Estimates suggest that there are in excess of 40 million individuals clinically defined as blind worldwide [1], and according to the World Health Organization, glaucoma is the leading cause of irreversible blindness [2]. In certain countries, it is well established that differences in glaucoma prevalence and severity exist amongst different ethnicities, age groups, and between genders. For example, in the United States, subjects of African or Hispanic descent have been shown to be at a greater risk of glaucoma compared to white Caucasians, while population-based studies have shown that Asians are more susceptible to primary-angle closure (PAC) in comparison to Europeans and Africans [3-6]. The prevalence of open-angle glaucoma has been shown to increase with age and is higher in males compared to females. Females are thought to be more susceptible to normal-tension glaucoma (NTG) and PAC compared to males $[7,8]$.

The indigenous peoples of the South Pacific are reported to have very low rates of glaucoma [9]. The Central Australian Ocular Health Study reported a prevalence of openangle glaucoma among the indigenous Australian people to be a third of the prevalence of nonindigenous Australians [10]. Another study found that there were no cases of chronic open-angle glaucoma or acute angle-closure glaucoma among their Papua New Guinean patients [11].

In 1969, a survey evaluating eye diseases including glaucoma and involving $333 \mathrm{New}$ Zealand Maori was published, reporting an absence of glaucoma in this population [12]. However, there have been no subsequent reports regarding the demographic data for glaucoma in the New Zealand population.

The aim of this study was to determine the distribution of diagnoses and demographic characteristics of glaucoma in a defined New Zealand population.

\section{Methods}

This was a retrospective study conducted via the tertiary glaucoma Service at Greenlane Clinical Centre (GCC), Auckland District Health Board (ADHB) in conjunction with the Department of Ophthalmology, New Zealand National Eye Centre, University of Auckland.

The medical records of all patients, both new and existing patients, presenting consecutively to the glaucoma service during a 6-month period from January 1, 2014, to July 1, 2014, were reviewed. Data collected included age at diagnosis, gender, and self-reported ethnicity. For existing patients, diagnoses were obtained from patients' past notes. For both eyes, information regarding the diagnosis, intraocular pressure (IOP), cup-to-disc ratio (CDR), and automated visual field VF testing was collected.

Patients presenting to the glaucoma service presented either acutely or were referred by their general practitioner, optometrist, or private ophthalmologist for either a glaucoma assessment or ongoing management of their disease. The definitive diagnosis was made by an experienced, glaucoma fellowship-trained ophthalmologist. 
Diagnoses were categorized either individually or grouped within a disease spectrum. These categories were as follows: primary open-angle glaucoma (POAG), NTG, ocular hypertension, PAC, mixed mechanism glaucoma, and secondary glaucoma (SG). The PAC group included PAC suspects requiring peripheral iridotomy, PAC, PAC glaucoma (PACG), and acute angle-closure crisis.

The exclusion criteria included patients classified as glaucoma suspects only, those whose initial glaucoma diagnosis could not be determined, and congenital glaucoma.

The ethnicity groups were categorized using the classification system that ADHB utilizes and publishes online (http://www.adhb.govt.nz/about/population_stats.htm). The ethnic distribution of the study population was compared to the combined catchment population of the Auckland and Waitemata DHB, for which the GCC provides the glaucoma service. The Auckland regional population is also provided as a reference. Ethnicity statistics were acquired from the 2013 New Zealand Census of culture and identity (Statistics New Zealand, available at www.stats.govt.nz/). Ethnic proportions for the catchment area and Auckland region do not total $100 \%$ due to individuals identifying themselves with multiple ethnicities. The "Asian" ethnicity included patients who were recorded as South East Asian, Chinese, "other Asian," and "Asian not further defined." The "Indian" ethnicity included only individuals who identified themselves as Indian.

Data collection and statistical analysis was performed using Microsoft Excel2010 version 14.0.7143.5000 (Microsoft Corporation, Washington, WA, USA) and Statistical Package for the Social Sciences v21.0 (IBM, New York, NY, USA). The $\chi^{2}$ test was used to assess the difference in the ethnic distribution between the study population and the catchment population. The independent samples $t$ test was used to analyze the intergender variability in age, IOP, and CDR. After testing for normality in data, the one-way analysis of variance (ANOVA) was applied together with the Bonferroni post hoc comparison test to assess the interethnicity variability in age, IOP, and CDR. If distributions were not normally distributed, the Kruskall-Wallis test was applied instead. Differences between means were considered statistically significant if $p$ values were $<0.05$.

\section{Results}

\section{Glaucoma Subtype Distribution}

A summary of the included and excluded cases and the distribution of diagnoses are outlined in Table 1. SG causes were distributed according to the following proportions: pseudoexfoliative $(34 \%, n=15)$, uveitic $(18 \%, n=8)$, neovascular $(11 \%, n=5)$, pigment dispersion $(11 \%, n=5)$, and other $(25 \%, n=11)$.

\section{Ethnicity Distribution}

The ethnicity distribution of the study population overall and for each glaucoma subtype is presented in Table 2.

Distribution of the reported ethnicity in all patients within the total study population $(n=567)$ and in the subpopulations of glaucoma diagnoses compared to the population of the catchment area and the Auckland regional population is presented in Table 2.

No ethnicity was recorded in the patient notes of 40 patients. There was a significant difference in the overall ethnic distribution of the study population in comparison to the catchment population $\left(\chi^{2}=80\right.$, d.f. $\left.=5, p<0.001\right)$. Table 3 presents the glaucoma subtype distribution for each ethnicity group.

The Caucasian ethnicity was overrepresented in the whole glaucoma population and in POAG, NTG, and ocular hypertension when compared to the catchment population. The Indian ethnicity was also overrepresented in the whole glaucoma population, POAG, and PAC.

In contrast, the Pacific Island Nation ethnicity was significantly underrepresented in all groups except SG. The Maori ethnicity was significantly underrepresented in all groups except PAC. The underrepresentation was most prominent in POAG followed by NTG. There were only 2 patients of Pacific Island Nation origin and 1 Maori patient with POAG. These are 10 times and 16 times less, respectively, when compared to the catchment population. To a lesser degree, the Asian ethnicity was also underrepresented in POAG and PAC. 


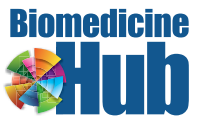

Table 1. Characteristics of excluded and included cases
Biomed Hub 2016;1:453313 (DOI: 10.1159/000453313)

(C) 2016 The Author(s). Published by S. Karger AG, Base www.karger.com/bmh

Mathan et al.: Analysis of Glaucoma Subtypes and Corresponding Demographics in a New Zealand Population

\begin{tabular}{lc}
\hline Number of cases reviewed & 857 \\
\hline Total excluded & 250 \\
Glaucoma suspects & 223 \\
Congenital/juvenile glaucoma & 3 \\
Glaucoma not further defined & 24 \\
\hline Total included & 607 \\
Males & 279 \\
Females & 328 \\
Bilateral disease & 489 \\
Unilateral disease & 118 \\
Single diagnosis & 602 \\
Patients with reported ethnicity & 567 \\
Patients with reported ethnicity and single diagnosis & 562 \\
\hline Diagnoses & \\
POAG & $235(39.0)$ \\
PAC group & $149(24.8)$ \\
Narrow angles & $109(18.1)$ \\
Narrow-angle glaucoma & $2(0.3)$ \\
Primary angle closure & $13(2.1)$ \\
Primary angle-closure glaucoma & $25(4.2)$ \\
NTG & $105(17.4)$ \\
SG & $69(11.5)$ \\
OHT & $30(5.0)$ \\
MM & $14(2.3)$ \\
\hline
\end{tabular}

Of patients with a single diagnosis, the distribution of these diagnoses is shown as $n$ (\% single diagnosis). POAG, Primary open-angle glaucoma; NTG, normal-tension glaucoma; OHT, ocular hypertension; PAC, primary angle closure; MM, mixed mechanism; SG, secondary glaucoma.

Table 2. Distribution of the reported ethnicity in all patients within the total study population $(n=567)$ and in the subpopulations of glaucoma diagnoses compared to the population of the catchment area and the Auckland regional population

\begin{tabular}{llllllllll}
\hline Ethnicity & \multicolumn{1}{l}{ Percentage by population, \% } \\
\cline { 2 - 11 } & $\begin{array}{l}\text { total } \\
\begin{array}{l}\text { population } \\
(n=567)\end{array}\end{array}$ & $\begin{array}{l}\text { POAG } \\
(n=217)\end{array}$ & $\begin{array}{l}\text { NTG } \\
(n=100)\end{array}$ & $\begin{array}{l}\text { OHT } \\
(n=28)\end{array}$ & $\begin{array}{l}\text { PAC } \\
(n=138)\end{array}$ & $\begin{array}{l}\text { MM } \\
(n=13)\end{array}$ & $\begin{array}{l}\text { SG } \\
(n=66)\end{array}$ & $\begin{array}{l}\text { catchment } \\
\text { area } \\
\text { population }\end{array}$ & $\begin{array}{l}\text { Auckland } \\
\text { population }\end{array}$ \\
\hline Caucasians & 71.3 & 76.0 & 72.0 & 82.1 & 61.6 & 84.6 & 63.3 & 62.0 & 55.8 \\
Asians & 11.5 & 10.1 & 17.0 & 17.9 & 10.9 & 0.0 & 10.0 & 15.8 & 14.8 \\
Indians & 9.7 & 10.1 & 6.0 & 0.0 & 13.0 & 15.4 & 10.0 & 5.6 & 6.9 \\
Pacific peoples & 3.2 & 0.9 & 2.0 & 0.0 & 5.1 & 0.0 & 11.7 & 8.9 & 13.8 \\
Maori & 2.5 & 0.5 & 2.0 & 0.0 & 6.5 & 0.0 & 3.3 & 8.0 & 10.1 \\
Other & 1.9 & 2.3 & 1.0 & 0.0 & 2.9 & 0.0 & 1.7 & 3.2 & 2.9 \\
\hline
\end{tabular}

POAG, primary open-angle glaucoma; NTG, normal-tension glaucoma; OHT, ocular hypertension; PAC, primary angle closure; MM, mixed mechanism; SG, secondary glaucoma. 
Mathan et al:: Analysis of Glaucoma Subtypes and Corresponding Demographics in a New Zealand Population

Table 3. Distribution of diagnoses within the study population and within each ethnic group

\begin{tabular}{llllllrr}
\hline Diagnoses & \multicolumn{7}{l}{ Percentage by ethnicity, \% } \\
\cline { 2 - 8 } & $\begin{array}{l}\text { study population } \\
(n=602)\end{array}$ & $\begin{array}{l}\text { Caucasians } \\
(n=40)\end{array}$ & $\begin{array}{l}\text { Asians } \\
(n=65)\end{array}$ & $\begin{array}{l}\text { Indians } \\
(n=54)\end{array}$ & $\begin{array}{l}\text { Pacific peoples } \\
(n=18)\end{array}$ & $\begin{array}{l}\text { Maori } \\
(n=14)\end{array}$ & $\begin{array}{l}\text { other } \\
(n=11)\end{array}$ \\
\hline POAG & 39.0 & 41.3 & 33.8 & 40.7 & 11.1 & 7.1 & 45.5 \\
NTG & 17.4 & 18.0 & 26.2 & 11.1 & 11.1 & 14.3 & 9.1 \\
OHT & 5.0 & 5.8 & 7.7 & 0.0 & 0.0 & 0.0 & 0.0 \\
PAC & 24.8 & 21.3 & 23.1 & 33.3 & 38.9 & 64.3 & 36.4 \\
MM & 2.3 & 2.8 & 0.0 & 3.7 & 0.0 & 0.0 & 0.0 \\
SG & 11.5 & 11.0 & 9.2 & 11.1 & 38.9 & 14.3 & 9.1 \\
\hline
\end{tabular}

POAG, primary open-angle glaucoma; NTG, normal-tension glaucoma; OHT, ocular hypertension; PAC, primary angle-closure group; MM, mixed mechanism; SG, secondary glaucoma.

Table 4. Gender and mean presenting age (where available) distribution within the study population and in the subpopulations of glaucoma diagnoses

\begin{tabular}{llllr}
\hline & $\begin{array}{l}\text { Male, } \\
\%\end{array}$ & $\begin{array}{l}\text { Female, } \\
\%\end{array}$ & $\begin{array}{l}\text { Mean presenting } \\
\text { age } \pm \text { SD, years }\end{array}$ & $n$ \\
\hline Total population & 46.0 & 54.0 & $65.9 \pm 13.9$ & 441 \\
POAG & 58.3 & 41.7 & $69.1 \pm 12.5$ & 146 \\
NTG & 36.2 & 63.8 & $70.8 \pm 12.5$ & 74 \\
OHT & 43.3 & 56.7 & $58.1 \pm 11.7$ & 25 \\
PAC & 32.9 & 67.1 & $64.7 \pm 11.4$ & 133 \\
MM & 21.4 & 78.6 & $58.7 \pm 11.0$ & 3 \\
SG & 52.2 & 47.8 & $57.1 \pm 18.9$ & 55 \\
\hline
\end{tabular}

POAG, primary open-angle glaucoma; NTG, normal-tension glaucoma; OHT, ocular hypertension; PAC, primary angle-closure group; MM, mixed mechanism; SG, secondary glaucoma.

\section{Gender and Age Distribution}

Table 4 presents the gender and age distribution for the whole study population and for each glaucoma subtype and also the gender and mean presenting age (where available) distribution within the study population and in subpopulations of glaucoma diagnoses.

Females were predominant in NTG (63.8\%), PAC (67.1\%), and mixed mechanism glaucoma (78.6\%). The age at presentation was available for 441 patients and is outlined in Table 4.

For the whole glaucoma population, the Caucasian group was diagnosed at an older age, mean \pm standard deviation, $(69.4 \pm 12.9$ years $)$ compared to Asians (60.8 \pm 12.7 years), Indians (55.9 \pm 12.4 years), and Pacific peoples (57.1 \pm 20.4 years; $p \leq 0.011$ ). The mean age at presentation in Maori was $60.3 \pm 9.8$ years $(p>0.05)$.

In the subgroup analyses, Asians and Indians were diagnosed with POAG younger (62.1 \pm 15.0 years) in comparison to Caucasians (73.1 \pm 10.6 years). Asians were diagnosed with NTG younger (61.1 \pm 11.4 years) than Caucasians (75.3 \pm 10.2 years; $p=0.001)$, and Indians were diagnosed with PAC (56.3 \pm 12.9 years) younger than Caucasians (67.1 \pm 11.2 years; $p=0.013$ ).

The distribution of IOP and CDR in the overall population did not vary significantly between ethnicities and gender. While the IOP and CDR for Maori and Pacific peoples could not be compared with other ethnicities due to small sample sizes, IOP and CDR did not vary 
significantly between the remaining ethnicities and gender for both POAG and NTG. The inclusion of these VF data points would have been a fallacious reflection of the actual VF reduction due to glaucoma since ocular conditions such as cataract, early lens changes, vitreous and retinal diseases, and optic atrophy may have resulted in unquantifiable reductions in the VF that was above and beyond the effect of glaucoma.

\section{Discussion}

The current study highlighted that POAG was the most common diagnosis, PAC the second at $24.8 \%$, and NTG the third most common at $17.4 \%$. The apparently high proportion of patients with PAC is likely due to our inclusion of all diseases that fell in the spectrum of this diagnosis, which ranged from narrow-angle to PACG.

The Caucasian and Indian ethnic groups were shown to be overrepresented overall and also in many of the glaucoma subgroups. Of particular interest is the underrepresentation of Maori and Pacific peoples in most glaucoma subtypes and most prominently in POAG. The observed trends in the ethnic distribution of the glaucoma population are likely due to a combination of 3 factors: genetic predisposition, access to healthcare, and population age structure.

Recent human leukocyte antigen loci analysis supports the Mongoloid ancestry of the Maori and Pacific people of New Zealand [13]. The current study has additionally shown that the PAC grouped diagnoses was the most common glaucoma subtype among Maori and Pacific peoples. The prevalence of PACG is reported to be relatively higher among studies in East Asia [14]. One study in Mongolia reported a 2.8 times higher prevalence of PACG in comparison to POAG [15]. Qualitatively, the similarity observed in disease patterns between these groups and the Maori and Pacific peoples speculate on the existence of genes, which may either protect Maori and Pacific peoples from glaucoma or predispose these ethnicities to certain types of glaucoma.

Access to the glaucoma service is commonly by way of referral from primary healthcare services. The question of access to primary eye care services for Maori and Pacific peoples may explain in part their underrepresentation in glaucoma diagnoses. These ethnic groups are shown to generally have poorer access to and restricted utilization of primary healthcare services [16-19]. The observed underrepresentation in the glaucoma clinic may thus reflect the low numbers of Maori and Pacific peoples initially presenting to their optometrist or general practitioner.

A further possible explanation for differences in the ethnic representation in this study may be related to the differences in the age structure of the Maori and Pacific populations in comparison to the Caucasian population. Maori [20] and Pacific peoples [21] in New Zealand have been reported to have a lower life expectancy in comparison to Caucasians. These populations are thus comparatively younger populations. According to statistics New Zealand, $17.1 \%$ of the Caucasian population are $>65$ years, while only 5.4 and $4.7 \%$ of the Maori and Pacific population, respectively, are over 65 . Since glaucoma typically a disease of the elderly, the under representation of Maori and Pacific peoples in the glaucoma clinic may be due to the lower life expectancy of the Maori and Pacific peoples. The older Caucasian population may explain their relative overrepresentation in our study.

An unexpected observation is the underrepresentation of Asians with glaucoma in the total population and surprisingly in the PAC subgroup. Since the prevalence of open-angle glaucoma among Asians is thought to be similar to Indians but higher than Caucasians and the prevalence of angle closure glaucoma is thought to be much higher in comparison to other studied ethnicities, Asians were expected to be overrepresented or at least equally repre- 
sented in the PAC population $[1,14]$. The authors hypothesized that the reason for this underrepresentation was due to possible underutilization of primary eye care services, in particular optometrists for regular check-ups, or the public system as a whole. Upon closer scrutiny of the data by removing the angle closure suspects, Asians were in fact overrepresented, as they formed $22.5 \%$ of the patients with PAC, narrow-angle glaucoma, and PACG, which are conditions at the more symptomatic end of the spectrum. More exploration is needed in characterizing the demographics of patients presenting to optometrists as well as the private medical sector.

There were limitations associated with this study. The diagnoses were made retrospectively and include biases of previous doctors, so classifications were not made by a single examiner or a team in a prospective manner. Additionally, the study does not sample all of the diagnosed glaucoma patients in the community, including privately treated patients, low-risk patients maintained in the community, and those without access to eye care. A more thorough dissection of the major ethnic groups would not have been possible in this study due to the restricted ethnicity grouping system employed by the hospital and the lack of sufficient sample sizes required for reliable statistical analysis. The "Asian" and "Indian" ethnicities were not further subdivided. This is a limitation of this study, which does not consider the differences in glaucoma susceptibility within these diverse ethnic groups. The absolute and relative prevalence of glaucoma subtypes have been shown to vary between different groups of what we have classified as "Asians" [14]. Moreover, some who identified themselves in the Asian group were Sri Lankans who are likely more similar to Indians. Furthermore, while the Fijian ethnicity was not further defined in the data collection, it was reasonable to assume by name that most Fijians were in fact Fijian Indians. This group may be considered to be genetically and culturally more similar to the Indian ethnicity rather than the Pacific Island Nation group. In addition, this work is a retrospective study based on clinical records from a tertiary glaucoma service with referrals from general practitioners, optometrists, and private ophthalmologists. Hence, it is possible that bias may arise due to factors such as access to health care and severity of the disease.

\section{Conclusion}

To the best of our knowledge, this is the first time a glaucoma population in New Zealand has been studied. We described the distribution of diagnoses, ethnicities, as well as trends in gender and age. Of particular interest was the clear underrepresentation of Maori and Pacific peoples with glaucoma. The results from this study may aid in the risk prediction for patients presenting to the glaucoma service.

\section{Acknowledgements}

The work herein has been supported in part by an unrestricted research grant from the Save Sight Society and from the University of Auckland.

\section{Statement of Ethics}

This study conformed to the Declaration of Helsinki (1995 and as revised in Edinburgh, 2000), and ethics approval was obtained from the University of Auckland Human Participants Ethics Committee and the ADHB Research Review Committee. 


\section{Disclosure Statement}

The authors have no conflicts of interest in relation to the results presented in this article.

\section{References}

$>1$ Quigley H, Broman AT: The number of people with glaucoma worldwide in 2010 and 2020. Br J Ophthalmol 2006;90:262-267.

-2 Resnikoff S, Pascolini D, Etya'ale D, Kocur I, Pararajasegaram R, Pokharel GP, Mariotti SP: Global data on visual impairment in the year 2002. Bull World Health Organ 2004;82:844-851.

-3 Tielsch JM, Sommer A, Katz J, Royall RM, Quigley HA, Javitt J: Racial variations in the prevalence of primary open-angle glaucoma: the Baltimore Eye Survey. J Am Med Assoc 1991;266:369-374.

4 Murakami Y, Lee BW, Duncan M, Kao A, Huang J-Y, Singh K, Lin SC: Racial and ethnic disparities in adherence to glaucoma follow-up visits in a county hospital population. Arch Ophthalmol 2011;129:872-878.

$\checkmark 5$ Quigley HA, West SK, Rodriguez J, Munoz B, Klein R, Snyder R: The prevalence of glaucoma in a populationbased study of Hispanic subjects: Proyecto VER. Arch Ophthalmol 2001;119:1819-1826.

6 He M, Foster PJ, Johnson GJ, Khaw PT: Angle-closure glaucoma in East Asian and European people. Different diseases? Eye 2006;20:3-12.

7 Levene RZ: Low tension glaucoma: A critical review and new material. Surv Ophthalmol 1980;24:621-664.

8 Shiose Y, Kitazawa Y, Tsukahara S, Akamatsu T, Mizokami K, Futa R, Katsushima H, Kosaki H: Epidemiology of glaucoma in Japan. A nationwide glaucoma survey. Jpn J Ophthalmol 1991;35:133-155.

$\checkmark 9$ Holmes WJ: Glaucoma in the central and South Pacific. Am J Ophthalmol 1961;51:253-261.

10 Landers J, Henderson T, Craig J: The prevalence of glaucoma in indigenous Australians within Central Australia: the Central Australian Ocular Health Study. Brit J Ophthalmol 2010;96:162-166.

11 Dethlefs RF: Glaucoma in Port Moresby Papua New Guinea. Papua New Guinea Med 1982;25:104-107.

12 Potter D: A preliminary field survey of Maori eyes. Trans Ophthalmol Soc N Z 1969;21:54-64.

-13 Edinur HA, Dunn PPJ, Hammond L, Selwyn C, Velickovic ZM, Lea RA, Chambers GK: Using HLA loci to inform ancestry and health in Polynesian and Maori populations. Tissue Antigens 2012;80:509-522.

14 Cho HK, Kee C: Population-based glaucoma prevalence studies in Asians. Surv Ophthalmol 2014;59:434-447.

15 Foster PJ, Baasanhu J, Alsbirk PH, Munkhbayar D, Uranchimeg D, Johnson GJ: Glaucoma in Mongolia: a population-based survey in Hövsgöl Province, northern Mongolia. Arch Ophthalmol 1996;114:1235-1241.

16 Ellison-Loschmann L, Pearce N: Improving access to health care among New Zealand's Maori population. Am J Public Health 2006;96:612-617.

17 Malcolm L: Inequities in access to and utilisation of primary medical care services for Maori and low income New Zealanders. N Z Med J 1996;109:356-358.

18 Teevale T, Denny S, Percival T, Fleming T: Pacific secondary school students' access to primary health care in New Zealand. N Z Med J 2013;126:58-68.

19 Crampton P, Dowell A, Woodward A, Salmond C: Utilisation rates in capitated primary care centres serving low income populations. N Z Med J 2000;113:436-438.

20 Harris R, Tobias M, Jeffreys M, Waldegrave K, Karlsen S, Nazroo J: Effects of self-reported racial discrimination and deprivation on Māori health and inequalities in New Zealand: cross-sectional study. Lancet 2006;367: 2005-2009.

-21 Tobias MI, Cheung J: Monitoring health inequalities: Life expectancy and small area deprivation in New Zealand. Popul Health Metr 2003;1:2. 